\title{
Choice of HbA1c threshold for identifying individuals at high risk of type 2 diabetes and implications for diabetes prevention programmes: a cohort study
}

Lauren R. Rodgers ${ }^{1 *}$ (D) Anita V. Hill ${ }^{2}$, John M. Dennis ${ }^{3}$, Zoe Craig ${ }^{4}$, Benedict May ${ }^{5}$, Andrew T. Hattersley ${ }^{6}$, Timothy J. McDonald ${ }^{7}$, Rob C. Andrews ${ }^{3}$, Angus Jones ${ }^{3+}$ and Beverley M. Shields ${ }^{3+}$

\begin{abstract}
Background: Type 2 diabetes (T2D) is common and increasing in prevalence. It is possible to prevent or delay T2D using lifestyle intervention programmes. Entry to these programmes is usually determined by a measure of glycaemia in the 'intermediate' range. This paper investigated the relationship between $\mathrm{HbA1c}$ and future diabetes risk and determined the impact of varying thresholds to identify those at high risk of developing T2D.

Methods: We studied 4227 participants without diabetes aged $\geq 40$ years recruited to the Exeter 10,000 population cohort in South West England. HbA1c was measured at study recruitment with repeat HbA1c available as part of usual care. Absolute risk of developing diabetes within 5 years, defined by $\mathrm{HbA} 1 \mathrm{c} \geq 48 \mathrm{mmol} / \mathrm{mol}$ (6.5\%), according to baseline $\mathrm{HbA1c}$, was assessed by a flexible parametric survival model.

Results: The overall absolute 5 -year risk ( $95 \% \mathrm{Cl}$ ) of developing T2D in the cohort was 4.2\% (3.6, 4.8\%). This rose to $7.1 \%(6.1,8.2 \%)$ in the $56 \%(n=2358 / 4224)$ of participants classified 'high-risk' with $\mathrm{HbA} 1 \mathrm{c} \geq 39 \mathrm{mmol} / \mathrm{mol}(5.7 \%$; ADA criteria). Under IEC criteria, $\mathrm{HbA} 1 \mathrm{c} \geq 42 \mathrm{mmol} / \mathrm{mol}(6.0 \%), 22 \%(n=929 / 4277)$ of the cohort was classified high-risk with 5 -year risk $14.9 \%(12.6,17.2 \%)$. Those with the highest HbA1c values $(44-47 \mathrm{mmol} / \mathrm{mol}[6.2-6.4 \%])$ had much higher 5 -year risk, $26.4 \%$ (22.0, 30.5\%) compared with $2.1 \%(1.5,2.6 \%)$ for $39-41 \mathrm{mmol} / \mathrm{mol}(5.7-5.9 \%)$ and $7.0 \%(5.4,8.6 \%)$ for $42-43 \mathrm{mmol} / \mathrm{mol}(6.0-6.1 \%)$. Changing the entry criterion to prevention programmes from 39 to $42 \mathrm{mmol} / \mathrm{mol}(5.7-6.0 \%)$ reduced the proportion classified high-risk by $61 \%$, and increased the positive predictive value (PPV) from 5.8 to $12.4 \%$ with negligible impact on the negative predictive value (NPV), $99.6 \%$ to $99.1 \%$. Increasing the threshold further, to $44 \mathrm{mmol} / \mathrm{mol}(6.2 \%)$, reduced those classified high-risk by $59 \%$, and markedly increased the PPV from 12.4 to $23.2 \%$ and had little impact on the NPV (99.1\% to 98.5\%).
\end{abstract}

\footnotetext{
* Correspondence: L.R.Rodgers@exeter.ac.uk

${ }^{\dagger}$ Angus Jones and Beverley M. Shields are joint senior authors.

'Institute of Health Research, University of Exeter Medical School, South

Cloisters, St Lukes Campus, Exeter EX1 2LU, UK

Full list of author information is available at the end of the article
}

(c) The Author(s). 2021 Open Access This article is licensed under a Creative Commons Attribution 4.0 International License, which permits use, sharing, adaptation, distribution and reproduction in any medium or format, as long as you give appropriate credit to the original author(s) and the source, provide a link to the Creative Commons licence, and indicate if changes were made. The images or other third party material in this article are included in the article's Creative Commons licence, unless indicated otherwise in a credit line to the material. If material is not included in the article's Creative Commons licence and your intended use is not permitted by statutory regulation or exceeds the permitted use, you will need to obtain permission directly from the copyright holder. To view a copy of this licence, visit http://creativecommons.org/licenses/by/4.0/. The Creative Commons Public Domain Dedication waiver (http://creativecommons.org/publicdomain/zero/1.0/) applies to the data made available in this article, unless otherwise stated in a credit line to the data. 
Conclusions: A large proportion of people are identified as high-risk using current thresholds. Increasing the risk threshold markedly reduces the number of people that would be classified as high-risk and entered into prevention programmes, although this must be balanced against cases missed. Raising the entry threshold would allow limited intervention opportunities to be focused on those most likely to develop T2D.

Keywords: Non-insulin treated type 2 diabetes, Progression, Disease prevention, Cohort analysis, EXTEND, Prediabetes, HbA1c, Intermediate hyperglycaemia

\section{Background}

Type 2 diabetes (T2D) is both common and rapidly increasing in prevalence. In 2017, an estimated 425 million people were living with $\mathrm{T} 2 \mathrm{D}$, and this is projected to increase to 629 million by $2030[1,2]$. As T2D is potentially preventable, the implementation of effective strategies to prevent the development of T2D is a priority [3]. Trials have shown that prevention programmes targeting those with the highest risk [4] may be effective in delaying the onset of T2D [5-9] for up to 15 years. While the relative merit of population vs targeted prevention is a subject of much debate $[10,11]$, many countries have targeted programmes. Within Europe, 13/22 countries have current national diabetes prevention programmes (DPPs) in place; two-thirds of these specifically target those at risk of developing diabetes [12]. Globally, examples of countries with DPPs include Australia, USA and China. While likely cost-effective, these programmes require substantial investment, costing between 0.13 and $0.2 \%$ of the annual healthcare budgets of the Netherlands, Germany and Australia [13, 14]. The UK has launched a national DPP which is expected to cost $£ 105$ million over a 5-year period [14-16].

A major issue for T2D prevention and the design of prevention programmes is defining the at-risk group to determine who should be enrolled. Entry to prevention programmes is usually based on a measure of glycaemia in the 'intermediate' range, often termed 'pre-diabetes' or 'non-diabetic hyperglycaemia'. However, there is no consensus as to which test, and at what threshold, should be used to define pre-diabetes. The American Diabetes Association (ADA) defines the elevated risk range for pre-diabetes as an $\mathrm{HbA} 1 \mathrm{c} 39-47 \mathrm{mmol} / \mathrm{mol}$ (5.7-6.4\%), fasting plasma glucose (FPG) $5.6-6.9 \mathrm{mmol} /$ L or oral glucose tolerance test (OGTT) 2-h glucose of 7.0-11.1 mmol/L. The International Expert Committee (IEC), World Health Organization (WHO) and many other countries use ranges of $\mathrm{HbA} 1 \mathrm{c} 42-47 \mathrm{mmol} / \mathrm{mol}$ (6.0-6.4\%), FPG $6.0-6.9 \mathrm{mmol} / \mathrm{L}$ or OGTT $7-11.1$ $\mathrm{mmol} / \mathrm{L}$ to indicate a high risk of developing diabetes [13]. Some guidelines, such as those in the UK [17], recommend a two-stage approach using a clinical risk score and $\mathrm{HbA} 1 \mathrm{c} 42-47 \mathrm{mmol} / \mathrm{mol}$ (6.0-6.4\%), where testing is targeted to specific groups at high-risk (e.g., Leicester Risk Score or Cambridge Risk Score) [18, 19].
In practice, opportune screening without a formal risk assessment is commonly undertaken, with HbA1c the most widely used measure due to ease of testing and convenience [20]. Systematic reviews have concluded this intermediate glycaemia predicts progression to T2D with varying accuracy depending on the definition and study population [6, 21-24]. A meta-analysis of studies examining the relationship between HbA1c and future diabetes identified 6 studies. They noted that progression rates using $\mathrm{HbA} 1 \mathrm{c}$ ranges of $6.0-6.4 \%$ were similar to those using FPG ranges $5.6-6.9 \mathrm{mmol} / \mathrm{L}$ and that further studies on the predictive performance of HbA1c on progression to T2D are required [22]. There has also been criticism of the number of participants deemed to be at risk of developing T2D using these tests. For example, HbA1c testing using the IEC/WHO definitions of risk of developing diabetes (HbA1c $42-47 \mathrm{mmol} / \mathrm{mol}$ [6.0-6.4\%]) $19 \%$ of UK adults would be considered to be at high risk of developing T2D, rising to $49 \%$ under the ADA defined glycaemic range (HbA1c $39-47 \mathrm{mmol} / \mathrm{mol}$ [5.7-6.4\%]) [25]. It is unlikely resources will ever be available to enter this proportion of a population into an effective diabetes prevention programme [26]. The UK has 100,000 places, rising to 200,000 , annually for their programme [27], a fraction of the places that would be needed to enrol the estimated 19\% of the adult population, $~ 8.5$ million in England [28], who will have an HbA1c $\geq 42 \mathrm{mmol} / \mathrm{mol}$ (6.0\%).

We use a large UK population dataset to assess how best to target the people most at risk of developing T2D for these prevention programmes. We evaluate the relationship between $\mathrm{HbA} 1 \mathrm{c}$ and future diabetes risk in a self-selected population cohort and determine the impact of varying test thresholds and existing clinical risk models.

\section{Methods \\ Study population}

Participant data were accessed via the Exeter 10,000/ Peninsula Research Bank (EXTEND/PRB). EXTEND/ PRB is an unselected population cohort of 11,074 participants, 8295 without known diabetes, recruited from the community and primary care in the South West, UK. This is an ethically approved research cohort (REC no: 14/SW/1089) established to provide a resource for 
researchers seeking access to samples/data/potential research participants [29]. It was designed to support research into improving our understanding of common diseases and healthy ageing. Participants were recruited from GP practices through mail invites to adults registered with the practice, word of mouth, study promotion at places of work, social groups and public events and through local media. Baseline samples taken include fasting blood and urine, with associated data recorded including height, weight, blood pressure and lifestyle/ medical history details. Participants are invited to provide consent for further contact and access to ongoing medical records. Follow-up blood test results were obtained from electronic laboratory records for 10,885/11, 074 participants who provided consent.

Our entry criteria based on baseline EXTEND/PRB recruitment included aged $\geq 40$ years and no diagnosed diabetes (either previously diagnosed or HbA1c $\geq 48$ $\mathrm{mmol} / \mathrm{mol}$ [6.5\%] [30]). This identified 6434 individuals (Fig. 1). An additional criterion for our study was that individuals had at least one follow-up HbA1c $>4$ weeks after the baseline measurement. There were no additional values (non-follow-up) on 2207 participants (Additional file 1: Table S1). While HbA1c is not routinely measured in people without diabetes, in the UK, it is measured as part of the UK NHS Health check for those aged 40-74 years or through opportunistic screening [31]. Four thousand two hundred twenty-seven participants with follow-up data were identified for our study.

Cohort recruitment occurred between January 2010 and April 2018. Electronic laboratory records were accessed up to March 2019.

\section{Laboratory measurement}

All included $\mathrm{HbA1c}$ values (baseline and follow-up) were assessed by the Academic Department of Blood Sciences at the Royal Devon and Exeter NHS Foundation Trust, using the TOSOH G8Ion Exchange High Performance

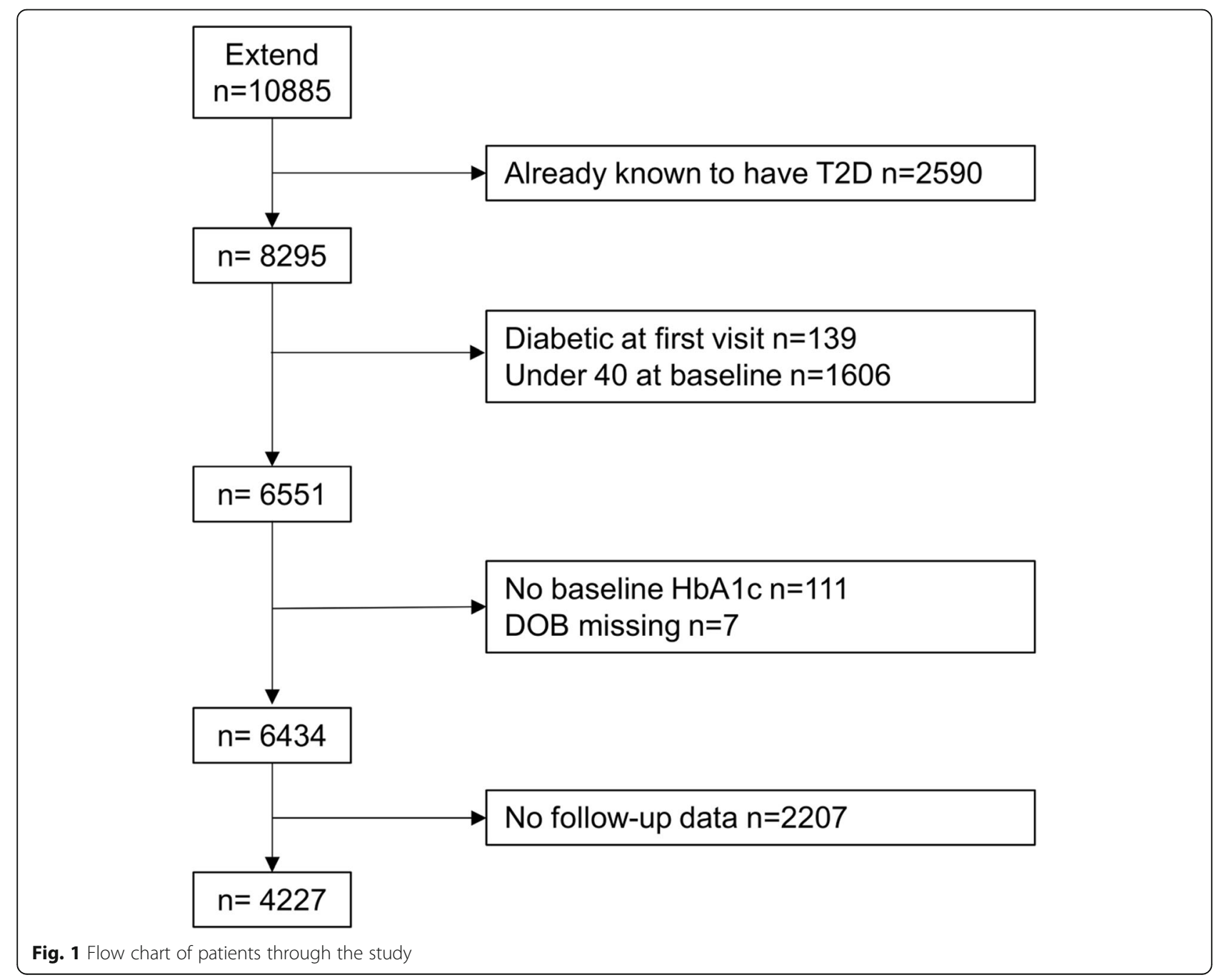


Liquid Chromatography platform, calibrated to the IFCC reference preparation, intra assay $\mathrm{CV}<2 \%$.

\section{Statistical analysis}

In the primary analysis, we fitted a flexible parametric survival model to estimate the absolute risk and hazard ratio (HR) of developing diabetes within 5 years given a baseline HbA1c measurement. The flexible parametric model was used, rather than Cox proportional hazards regression, as risk increased more at higher $\mathrm{HbA1c}$ values; this allowed for the fact that the proportional hazards assumption would not be met. For this study, we defined a diagnosis of diabetes as an HbA1c $\geq 48$ $\mathrm{mmol} / \mathrm{mol}(6.5 \%)$. For those who did not have an HbA1c $\geq 48 \mathrm{mmol} / \mathrm{mol}(6.5 \%)$, data were censored at either their last $\mathrm{HbA1c}$ (if within 5 years after baseline), or at 5 years if they had further measurements. We evaluated the 5year risk of developing T2D using the existing $\mathrm{HbA1c}$ ranges for identifying those at high risk of developing diabetes; ADA (HbA1c 39-47 mmol/mol [5.7-6.4\%]), IEC/UK (42-47 $\mathrm{mmol} / \mathrm{mol}$ [6.0-6.4\%]). We assessed the area under the receiver operating characteristic curve (AUC ROC), false positive and false negative rates, sensitivity, specificity, positive predictive value (PPV) and negative predictive value (NPV) for currently used HbA1c thresholds and assessed the impact of raising the threshold.

We also looked at the impact of combined HbA1c and clinical risk score. The Leicester Risk Score (LRS) was developed and validated on similar UK population cohorts and is recommended in NHS guidance $[17,18]$. The LRS model variables are sex, age $(\leq 50,50-60,60-$ 70 and $\geq 70$ years), a relative with diabetes (none and first-degree family history of T2D), waist circumference (<90, 90-99, 99-110 and $\geq 110 \mathrm{~cm}$ ), high blood pressure (previous history of or participant on antihypertensive medication) and BMI $(<25,25-30,30-35$ and $\geq 35 \mathrm{~kg} /$ $\mathrm{m}^{2}$ ). The risk of developing diabetes was modelled using these covariates and an optimal cut point for high risk of developing T2D was calculated using the model [19]; a person with a LRS score $\geq 16$ is considered at high risk of developing T2D. In the UK, there are three pathways to the DPP; a blood test results in the at-risk range as part of routine clinical care, a LRS $\geq 16$ followed by a blood test result in the at-risk range or those who have been in the at risk group in the past [32,33]. The use of a two-stage procedure with the clinical risk score (LRS) reduces the need for additional blood testing in those at low risk. LRS results are presented in Additional file 2.

As a DPP was introduced in the cohort area in June 2018, a sensitivity analysis with study end point June 2018 was carried out (Additional file 3).

Data were analysed using Stata v16 including the stpm2 package.

\section{Results}

Within included participants $(n=4227), 3.4 \%(n=144)$ of participants progressed to diabetes within a 5-year period. Mean (SD) time to progression to diabetes was 45.6 (17.9) months and mean follow-up time (SD) 28.4 (14.0) months (Table 1). Follow-up data were available for 4227 out of 6434 participants who provided baseline HbA1c. These participants had heavier BMI (mean 95\% CI difference $0.8 \mathrm{~kg} / \mathrm{m}^{2}\left[0.6,1.0 \mathrm{~kg} / \mathrm{m}^{2}\right] \mathrm{kg} / \mathrm{m}^{2}$ ) and were 3.7 years $(3.1,4.3$ years) older. Their baseline HbA1c was $1.7 \mathrm{mmol} / \mathrm{mol}$ (1.5, $1.9 \mathrm{mmol} / \mathrm{mol}), 0.15 \%$ (0.14, $0.17 \%$, higher than those without follow-up (Table 1, Additional file 1: Table S1), suggesting those who followed up with clinical hbA1c testing had a higher risk of diabetes.

The absolute 5-year risk of developing type 2 diabetes is modest in those meeting criteria for diabetes prevention programmes

The overall absolute 5-year risk (95\% CI) of developing T2D in the cohort was $4.2 \%(3.6,4.8 \%) .56 \%(n=2358 /$ 4224) of participants were classified as high-risk based on ADA criteria (HbA1c $\geq 39 \mathrm{mmol} / \mathrm{mol}$ [5.7\%]). However, the risk of progression in this group was modest: absolute 5-year risk of developing T2D 7.1\% (6.1,8.2\%). Using the IEC criteria, HbA1c $\geq 42 \mathrm{mmol} / \mathrm{mol}$ (6.0\%), $22 \%(n=929 / 4277)$ of the cohort was classified as 'highrisk', the absolute 5-year risk in this group was $14.9 \%$ (12.6, 17.2\%). In those meeting both UK NICE criteria of HbA1c $\geq 42$ and LRS $\geq 16,14 \%(n=578 / 4214)$, the 5year risk was slightly higher at $19.0 \%(15.8,22.1 \%)$. In those at high clinical risk (LRS $\geq 16$ ), $56 \%$ of participants identified as high-risk by US criteria had a low risk of progression: the overall 5-year risk in those with $\mathrm{HbA1c}$ $\geq 39 \mathrm{mmol} / \mathrm{mol}$ [5.7\%] was $10.4 \%(8.7,12.1 \%)$ with risk $3.1 \%(2.0,4.0 \%)$ in the group with HbA1c $39-41 \mathrm{mmol} /$ mol [5.7-5.9\%].

\section{Raising the HbA1c threshold for entry reduces the number of people referred to prevention programmes who are unlikely to develop diabetes}

Figure 2a (values in Additional file 4) shows absolute risk and Fig. $2 \mathrm{~b}$ relative risks for developing HbA1c defined diabetes within 5 years of study recruitment based on a flexible parametric survival model. A Kaplan-Meier plot by HbA1c categories is shown in Additional file 5 . Future risk of developing diabetes was very strongly related to HbA1c value within the current 'high-risk' categories. Those in the lower ranges of current 'pre-diabetes' criteria had a low 5-year absolute risk of developing diabetes, even where multiple other risk factors were present. For example, 5-year risk in those with the highest $\mathrm{HbAlc}$ values $(44-47 \mathrm{mmol} / \mathrm{mol}$ [6.2-6.4\%]) was $26.4 \%$ (22.0, 30.5\%) compared with $2.1 \%(1.5,2.6 \%)$ for $39-41 \mathrm{mmol} / \mathrm{mol}(5.7-5.9 \%)$ and $7.0 \%(5.4,8.6 \%)$ for 
Table 1 Baseline characteristics of the cohort

\begin{tabular}{|c|c|c|c|}
\hline & All participants & $\begin{array}{l}\text { Participants who do } \\
\text { not develop diabetes }\end{array}$ & $\begin{array}{l}\text { Participants who } \\
\text { develop diabetes }\end{array}$ \\
\hline Age (years) & $60.7(10.8)$ & $\begin{array}{l}60.5(10.8) \\
n=4083\end{array}$ & $\begin{array}{l}65.3(10.4) \\
n=144\end{array}$ \\
\hline Sex (\% female) & $62.1 \%$ & $\begin{array}{l}62.4 \% \\
n=4082\end{array}$ & $\begin{array}{l}54.9 \% \\
n=144\end{array}$ \\
\hline $\mathrm{BMI}\left(\mathrm{kg} / \mathrm{m}^{2}\right)$ & $\begin{array}{l}26.9(4.5) \\
n=4223\end{array}$ & $\begin{array}{l}26.8(4.5) \\
n=4079\end{array}$ & $\begin{array}{l}29.9(5.2) \\
n=144\end{array}$ \\
\hline Weight (kg) & $\begin{array}{l}76.0(15.1) \\
n=4223\end{array}$ & $\begin{array}{l}75.8(14.9) \\
n=4081\end{array}$ & $\begin{array}{l}84.1(18.1) \\
n=144\end{array}$ \\
\hline Waist (cm) & $\begin{array}{l}89.3(13.1) \\
n=4217\end{array}$ & $\begin{array}{l}89.0(12.9) \\
n=4073\end{array}$ & $\begin{array}{l}99.4(13.6) \\
n=144\end{array}$ \\
\hline $\mathrm{HbA} 1 \mathrm{c}(\mathrm{mmol} / \mathrm{mol}[\%])$ & $\begin{array}{l}38.9(3.5) \\
(5.7[0.3] \%) \\
n=4227\end{array}$ & $\begin{array}{l}38.7(3.4) \\
(5.7[0.3] \%) \\
n=4083\end{array}$ & $\begin{array}{l}43.5(2.6) \\
(6.1[0.2] \%) \\
n=144\end{array}$ \\
\hline Mean systolic blood pressure (mmHg) & $\begin{array}{l}134.0(18.8) \\
n=4226\end{array}$ & $\begin{array}{l}133.8(18.8) \\
n=4082\end{array}$ & $\begin{array}{l}141.0(19.3) \\
n=144\end{array}$ \\
\hline Fasting glucose (mmol/L) & $\begin{array}{l}5.1(0.5) \\
n=3582\end{array}$ & $\begin{array}{l}5.0(0.5) \\
n=3465\end{array}$ & $\begin{array}{l}5.6(0.7) \\
n=117\end{array}$ \\
\hline Index of Multiple Deprivation deciles (UK population deciles) & $\begin{array}{l}6.9(2.1) \\
n=4144\end{array}$ & $\begin{array}{l}6.9(2.1) \\
n=4004\end{array}$ & $\begin{array}{l}6.5(2.2) \\
n=140\end{array}$ \\
\hline Current smoker & $5.6 \%(n=235 / 4227)$ & $5.4 \%(n=219 / 4082)$ & $11.1 \%(n=16 / 144)$ \\
\hline Family history of diabetes & $21.7 \%(n=918 / 4227)$ & $21.4 \%(n=841 / 4083)$ & $30.6 \%(n=44 / 144)$ \\
\hline \multicolumn{4}{|l|}{ Ethnicity: } \\
\hline White & $98.9 \%(n=4180 / 4225)$ & $98.9 \%(n=4037 / 4081)$ & $99.3 \%(n=143 / 144)$ \\
\hline Other & $1.1 \%(n=45 / 4225)$ & $1.1 \%(n=44 / 4081)$ & $0.7 \%(n=1 / 144)$ \\
\hline Follow-up time (months) ${ }^{a}$ & $\begin{array}{l}45.0(18.0) \\
n=4227\end{array}$ & $\begin{array}{l}45.6(17.9) \\
n=4083\end{array}$ & $\begin{array}{l}28.4(14.0) \\
n=144\end{array}$ \\
\hline
\end{tabular}

Mean (SD) or percentage reported

${ }^{a}$ Shorter follow-up time in those who progressed to diabetes vs those who did not is due to censoring of time at the point of progression to T2D

those with an HbA1c 42-43 mmol/mol (6.0-6.1\%). The hazard ratio (HR) shows that a person with an HbA1c of $44 \mathrm{mmol} / \mathrm{mol}(6.2 \%)$ is three times (CI 2.6-3.5) more likely to develop T2D within 5 years than someone with an $\mathrm{HbA} 1 \mathrm{c}$ of $42 \mathrm{mmol}$ (6.0\%) (Fig. 2b).

Increasing the risk threshold reduced the number of participants that would be classified as high-risk and entered into prevention programmes and increased the risk of included individuals (Table 2). Changing the US threshold of $39 \mathrm{mmol} / \mathrm{mol}$ (5.7\%) to the more widely used threshold of $42 \mathrm{mmol} / \mathrm{mol}$ (6.0\%) reduces the proportion classified as high-risk (and therefore eligible for intervention) by $61 \%$. Increasing the threshold further from 42 to $44 \mathrm{mmol} / \mathrm{mol}$ (6.0\% to $6.2 \%$ ) reduces the proportion classified as high-risk (and therefore eligible for intervention) by a further $59 \%$. While these changes markedly increase positive predictive value and markedly reduce false positive rates, they have very little impact on the negative predictive value, with those below the thresholds unlikely to develop diabetes within 5 years (Table 2, Fig. 3). However, higher thresholds reduce sensitivity, with $38.9 \%(30.9,47.3 \%)$ of those developing diabetes within 5 years missed using a threshold of $>44$ $\mathrm{mmol} / \mathrm{mol}$ (sensitivity $61.1 \%$ [52.6, 69.1\%]). Figure 3 illustrates the impact of these thresholds on screening a population.

\section{Combining assessment of a patient's clinical risk with their $\mathrm{HbA1c}$ test result only very modestly improves prediction of future diabetes}

The impact of combining clinic risk (using the LRS) with HbA1c testing on our model of 5-year absolute risk is shown in Additional file 2. Overall the 5-year absolute risk for an LRS $\geq 16$ was $5.5 \%(4.5,6.5 \%, n=1916)$, slightly higher than the risk in the whole cohort, $4.2 \%$ $(3.6,4.8 \%, n=4227)$, and the 5-year risk was only modestly higher in combination with high HbA1c. When assessing the accuracy of the thresholds in our cohort, using a LRS score of $\geq 16$ alone had similar performance to measuring $\mathrm{HbA1c}$ and using a cutoff of $39 \mathrm{mmol} / \mathrm{mol}$ (5.7\%), without the need for a biochemical test. However, the positive predictive value of both approaches was low: 5.9\% (4.9, 7.1\%) (LRS $\geq 16$, NPV 98.7\% [98.1, 99.1\%]) and $5.8 \%(4.9,6.8 \%)(\mathrm{HbA} 1 \mathrm{c} \geq 39 \mathrm{mmol} / \mathrm{mol}$ [5.7\%], NPV 99.6\% [99.2, 99.8\%]). The performance of the UK recommended two-step strategy is shown in 

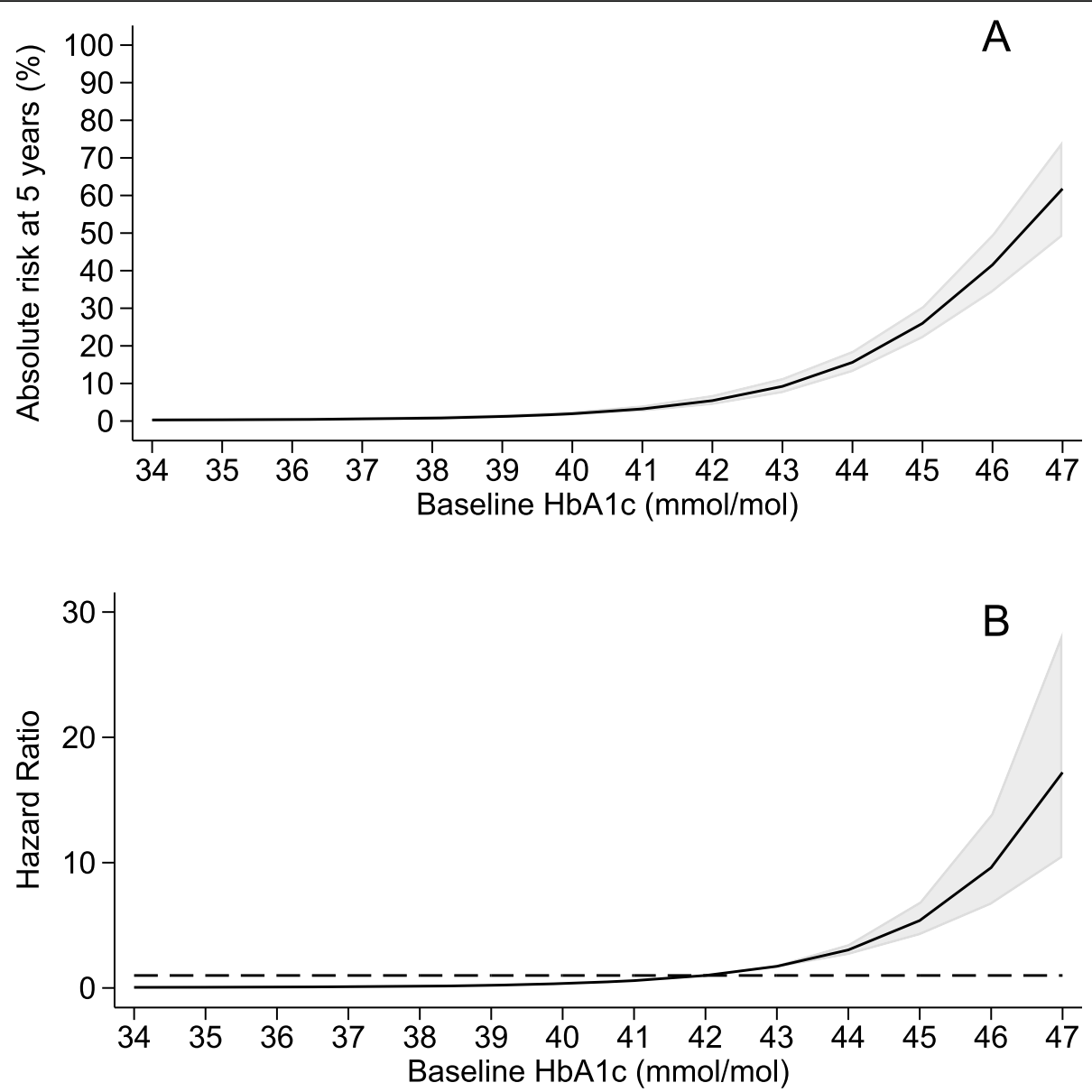

Fig. 2 A Absolute 5-year risk of developing T2D (defined by HbA1c $\geq 48 \mathrm{mmol} / \mathrm{mol}[6.5 \%]$ ) within 5 years given a baseline HbA1c modelled using a flexible parametric survival model. B Hazard ratio for risk of developing type T2D (defined by HbA1c $\geq 48 \mathrm{mmol} / \mathrm{mol}[6.5 \%]$ ) within 5 years given a baseline $\mathrm{HbA} 1 \mathrm{c}$ modelled using a flexible parametric survival model. The hazard ratio presented is relative to the cutoff value of 42 $\mathrm{mmol} / \mathrm{mol}(6.0 \%)$. --- indicates hazard ratio of 1 . HbA1c $\%$ conversion $=0.0915 \times \mathrm{HbA} 1 \mathrm{c} \mathrm{mmol} / \mathrm{mol}+2.15$

Additional file 2 and improves the positive predictive value from the use of an HbAlc of $42 \mathrm{mmol} / \mathrm{mol}(6.0 \%)$ alone (from $12.4 \%$ [10.3, 14.7\%] to $15.9 \%$ [13.0, 19.2\%]), at the expense of a decrease in sensitivity from $79.9 \%$ $(72.4,86.1 \%)$ to $63.9 \%(55.5,71.7 \%)$ but a negligible change in NPV $99.1 \%(98.7,99.4 \%)$ to $98.6 \%$ (98.1, 98.9\%) (Supplementary Table S3).

\section{Sensitivity analysis}

A sensitivity analysis excluded any participants who may have been affected by the start of the UK's DPP (Additional file 3), this reduced our cohort size to $n=4105$. There were no appreciable changes in the demographic characteristics of the cohort (Additional file 3: Table S4), e.g., HbA1c changed from mean (SD) $38.8 \mathrm{mmol} / \mathrm{mol}$ (3.5), $5.7 \%$ (0.3), to $38.9 \mathrm{mmol} / \mathrm{mol}$ (3.5), $5.7 \%$ (0.3). The mean follow-up time was reduced from 45.0 months to 43.3 months. A similar proportion of participants progressed to T2D, 3.2\% ( $n=130 / 4105)$, and the absolute risk of progression within 5 years was similar; at a threshold of $39 \mathrm{mmol} / \mathrm{mol}(5.7 \%)$ the risk was $4.2 \%$ (3.6, 4.8\%), 7.1\% (6.1,8.2\%) and $14.9 \%(12.6,17.2 \%)$ for thresholds of 42 and $44 \mathrm{mmol} / \mathrm{mol} \quad(6.0 \%$ and $6.2 \%)$, respectively.

\section{Discussion}

We have shown in our UK population cohort that current guidance for using HbA1c to identify those at risk of future diabetes classifies a large proportion of the population as high-risk (often termed pre-diabetes). Overall, for many individuals, the absolute risk of developing diabetes over a 5 -year period is very low, particularly for those at the lower end of the 'high-risk' HbA1c range. A potential approach to target those most at risk would be to raise the inclusion threshold, which would markedly reduce the numbers at low risk undergoing intervention, at the expense of loss of sensitivity, with a proportion of who progress to T2D missed by a move to higher thresholds. Raising HbA1c thresholds from 39 $\mathrm{mmol} / \mathrm{mol}$ to $42 \mathrm{mmol} / \mathrm{mol}$ (5.7-6.0\%; ADA) or from 


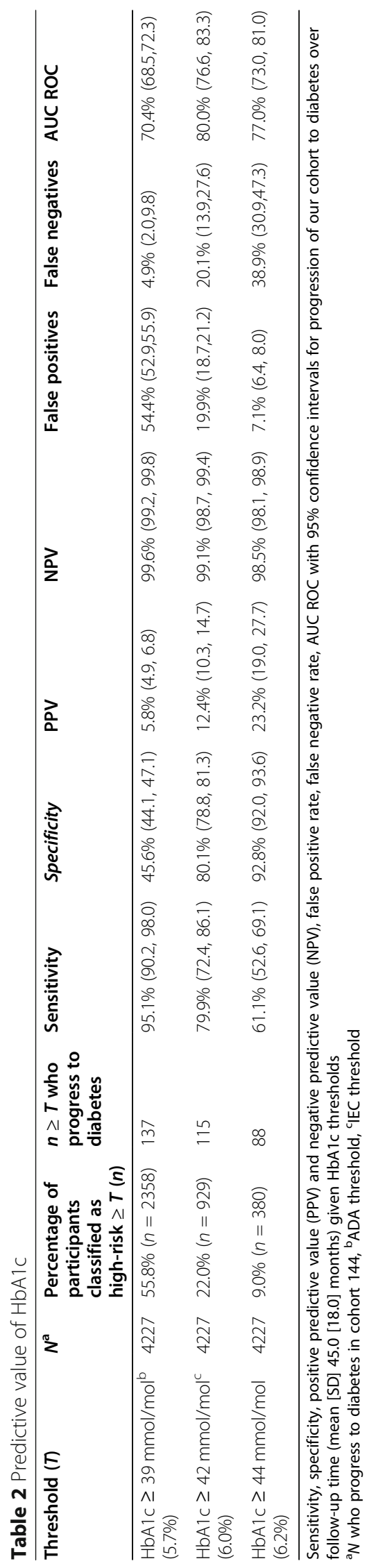




\begin{tabular}{|c|c|c|c|}
\hline HbA1c threshold & Number of individuals over threshold & $\begin{array}{l}\text { Proportion of individuals over } \\
\text { threshold who would develop } \\
\text { diabetes within } 5 \text { years }\end{array}$ & $\begin{array}{l}\text { Proportion of individuals under } \\
\text { threshold who would develop } \\
\text { diabetes within } 5 \text { years }\end{array}$ \\
\hline Whole Cohort & 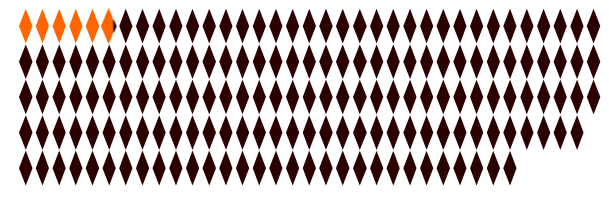 & 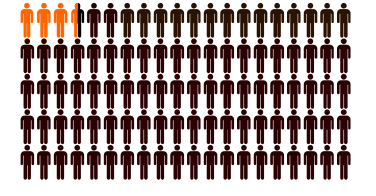 & \\
\hline $\mathrm{HbA} 1 \mathrm{c} \geq 39 \mathrm{mmol} / \mathrm{mol}^{*}$ & 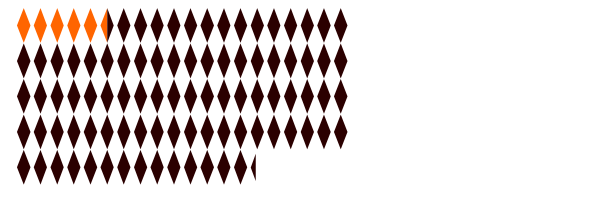 & 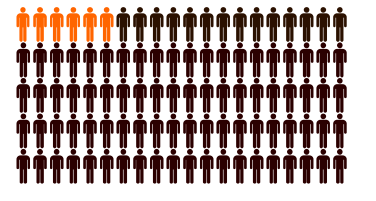 & 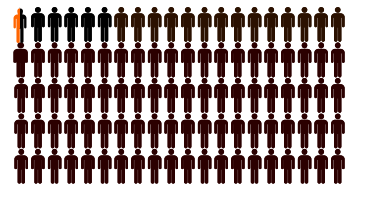 \\
\hline $\mathrm{HbA}_{1 \mathrm{c}} \geq 42 \mathrm{mmol} / \mathrm{mol}^{\dagger}$ & 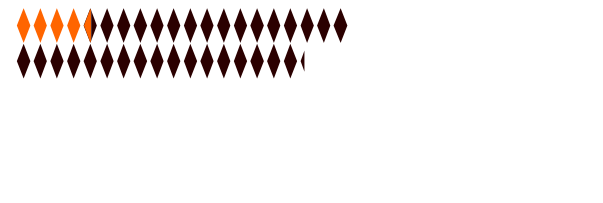 & 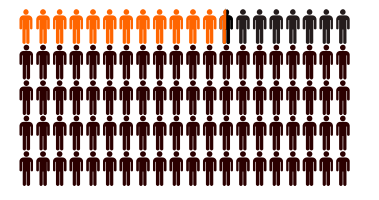 & 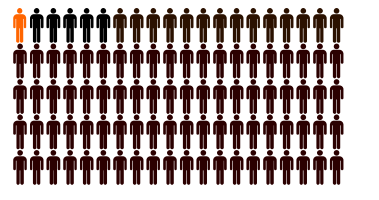 \\
\hline $\mathrm{HbA} 1 \mathrm{c} \geq 44 \mathrm{mmol} / \mathrm{mol}$ & 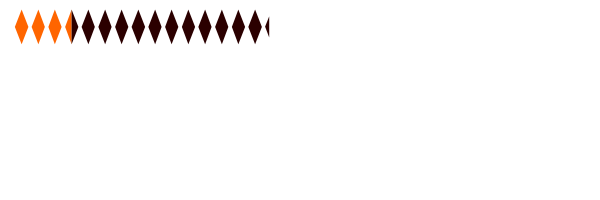 & 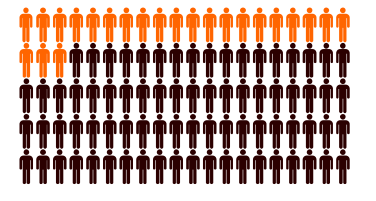 & 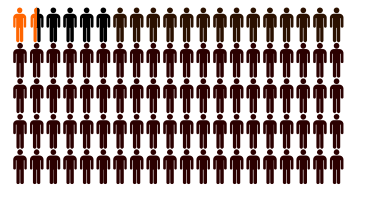 \\
\hline & 25 people who did not develop T2D within 5 years & \multicolumn{2}{|c|}{ a person who did not develop T2D within 5 years } \\
\hline & 25 people who developed T2D within 5 years & \multicolumn{2}{|l|}{ a person who developed T2D within 5 years } \\
\hline
\end{tabular}

$42 \mathrm{mmol} / \mathrm{mol}$ to $44 \mathrm{mmol} / \mathrm{mol}(6.0-6.2 \%$; IEC and UK) would avoid classifying a large proportion of the population who have low absolute risk as having a pre-disease state, and could potentially increase cost-effectiveness of targeted prevention clinical programs and research studies where resources are insufficient to target the entire at-risk population.

Longitudinal cohort studies mostly focus on FPG or IGT, with only $n=6 / 70$ studies in a meta-analysis of progression to $\mathrm{T} 2 \mathrm{D}$ using $\mathrm{HbA} 1 \mathrm{c}$ to define pre-diabetes [22]. A UK cohort study of 5735 participants had 1.3\% progressing to T2D over 3 years and showed an increased risk of developing diabetes with increasing HbA1c, 7 times greater risk of developing diabetes in the group with HbA1c $42-46 \mathrm{mmol} / \mathrm{mol}(6.0-6.4 \%)$ vs < 31 $\mathrm{mmol} / \mathrm{mol}$ (5.0\%) [34]. Most studies used the ADA or IEC HbA1c or IFG ranges to identify individuals at high risk of developing diabetes without additional focus on the impact of raising the threshold higher than 42 $\mathrm{mmol} / \mathrm{mol}$ (6.0\%). Three studies outside the UK had similar duration, 5 years in the Danish (Inter99, $n=$ 4930) and Australian (AusDiab, $n=6012$ ) studies and 6 years in the French DESIR $(n=3784)$ study [35]. These studies found similar incidences of diabetes to our study, 2.3-3.1\%; however, modestly lower sensitivities were reported (65-78\% using a threshold of $39 \mathrm{mmol} / \mathrm{mol}$ [5.7\%] and $38-45 \%$ at a threshold of $42 \mathrm{mmol} / \mathrm{mol}$ [6.0\%]). The increase in PPV observed with increasing HbA1c thresholds was consistent with our findings, 5.9$11 \%$ at $\geq 39 \mathrm{mmol} / \mathrm{mol}$ (5.7\%), $13-28 \%$ for $\geq 42 \mathrm{mmol} /$ $\mathrm{mol}(6.0 \%)$ and $27-44 \%$ for $\geq 46 \mathrm{mmol} / \mathrm{mol}(6.4 \%)$.

Other work has concluded that prevention programmes should target those at the highest risk. In a recent study of a UK prevention programme, Smith et al. [36] conclude that to maximise the effectiveness programme eligibility criteria should be adjusted to target more high-risk individuals. Zhuo et al. found lowering fasting glucose thresholds lowered the costeffectiveness of programmes [37]. A cost-effectiveness analysis by Thomas et al. suggests that the best value, and best health benefits, for a prevention programme, would be to prioritise obese (BMI $\geq 30 \mathrm{~kg} / \mathrm{m}^{2}$ ) individuals, those with the highest $\mathrm{HbA1c}$ in the pre-diabetes range and aged 40-74 [38]. A higher HbA1c threshold 
for entry to a prevention programme targets those at the highest risk.

The strengths of this study include the use of a large unselected population cohort and the assessment of clinical risk using models and thresholds previously validated and routinely used in this region. In particular, this study adds to the understanding of the predictive capacity of $\mathrm{HbA} 1 \mathrm{c}$ in progression to T2D, identified as an area requiring further research [17, 22]. A key limitation of our study is that follow-up HbA1c relied on clinical testing and was therefore not available in all study participants. This may have introduced bias as factors that influence the risk of T2D may also influence whether a clinician screens for diabetes. This is consistent with those who provided baseline data only in our cohort who were on average 3.7 years younger, $1.9 \mathrm{~kg}$ lighter and had $1.7 \mathrm{mmol} / \mathrm{mol}(0.15 \%)$ lower HbA1c, than our cohort. This suggests higher-risk patients were more likely to be followed up and therefore included in our cohort, and we may therefore overestimate future diabetes risk. However, the characteristics of included participants are broadly consistent with previous UK population studies of older adults reporting HbA1c, for example, the Norfolk $(n=3921)$, Leicester $(n=6390)$ and ELSA $(n=5262)$ studies reported mean $\mathrm{HbA} 1 \mathrm{c}$ of 36,39 and $36 \mathrm{mmol} / \mathrm{mol}$ (5.4, 5.7, 5.4\%), BMI 30.1, 28.1 and $27.5 \mathrm{~km} / \mathrm{m}^{2}$, and age 58.8 , 57.3 and 65.8 years, respectively $[18,39,40]$.

A further limitation is that our cohort contains limited numbers of people of non-white ethnicity (consistent with the population of this region) and predictive value of HbA1c and performance of HbA1c thresholds may be different in other ethnicities [6, 22, 25, 41]. For example, Mostafa et al. showed that equivalent HbA1c thresholds differed in a study on white Europeans and south Asians, $5.7 \%$ and $6.0 \%$, respectively [25]. The progression rates to diabetes based on an HbA1c $6.0-6.4 \%$ have been shown to differ across ethnicities: incidence rate ratios $(95 \%$ CI) $0.21(0.02,2.03)$ in Europe and $0.30(0.02,4.96)$ in the Americas relative to Asia [22]. Further work should replicate our study in cohorts with more diverse ethnic profiles.

Lastly, we have used HbA1c for both risk prediction and diagnosis. We may have seen a different relationship had glucose-based measures been used to define diabetes, with potentially lower sensitivity had multiple measures (such as OGTT) been used to define incident diabetes. However, this closely reflects clinical practicein the UK, T2D is now diagnosed principally by HbA1c testing, and almost all of those diagnosed will have had an earlier HbA1c test. Fasting glucose is tested rarely and glucose tolerance tests are used only in the setting of detecting gestational diabetes.

Our findings have potential implications for clinical practice. HbA1c is commonly used in practice to determine if a person should be identified as high risk (often termed 'pre-diabetes') and referred to a DPP, and, with current thresholds, a high proportion (up to $54 \%$ with ADA criteria) would be eligible, with low 5-year risk of diabetes for those with HbA1c in the lower part of 'prediabetes' risk range. Currently, those in the pre-diabetes range are given equal weighting for an invitation to a prevention programme. Where resources or capacity are constrained, higher thresholds could be used to refer to these programs, with those with lower HbAlc potentially offered monitoring of HbA1c with referral only if HbA1c progresses to a higher risk range. However, this would be balanced with a trade-off in cases missed. Ultimately, where resources and capacity allow, the optimal choice of threshold should be based on detailed costeffectiveness analysis, taking into account multiple factors including the costs of preventable cases that may be missed with higher test thresholds, program costs and the potential negative impact of 'false positive' results.

\section{Conclusion}

In a UK population, a large proportion of people are identified as high-risk using current thresholds, with modest 5-year risk of diabetes. Increasing the risk threshold markedly reduces the number of people that would be classified as high-risk and entered into prevention programmes, allowing limited intervention opportunities to be focused on those most likely to develop T2D.

\section{Abbreviations}

ADA: American Diabetes Association; AUC ROC: Area under the receiver operating characteristic curve; Cl: Confidence interval; DPP: Diabetes prevention programme; EXTEND: Exeter 10,000 cohort; FPG: Fasting plasma glucose; IEC: International Expert Committee; IQR: Inter quartile range; LRS: Leicester Risk Score; NHS: National Health Service; NICE: National Institute for Health Care Excellence; NPV: Negative predictive value; OGTT: Oral glucose tolerance test; pp: Per person; PPV: Positive predictive value; PRB: Peninsula Research Bank; T2D: Type 2 diabetes; UK: United Kingdom; WHO: World Health Organization

\section{Supplementary Information}

The online version contains supplementary material available at https://doi. org/10.1186/s12916-021-02054-w.

Additional file 1. Characteristics of those who provided baseline data only.

Additional file 2. Leicester Risk Score.

Additional file 3. Sensitivity analysis excluding data after the launch of the UK diabetes prevention programme.

Additional file 4. Absolute 5 year risk of developing Type 2 diabetes given baseline $\mathrm{HbA1C}$.

Additional file 5. Kaplan-Meier survival plot by HbA1c category.

\section{Acknowledgements}

The authors would like to thank Dr B Knight for her helpful comments and the volunteers for dedicating their time to completing the study. The authors would like to acknowledge the contribution of the admin, nurse, medical and research staff at the NIHR Exeter Clinical Research Facility for volunteer recruitment, data/sample collection. The views expressed are those 
of the author(s) and not necessarily those of the NIHR or the Department of Health and Social Care

\section{Authors' contributions}

AVH had the initial idea for the study. ATH, AVH and TJM researched the data. ZC and BM conducted initial data analysis. LRR conducted the main data analysis and provided statistical expertise. LRR wrote the first draft of the paper with assistance from AGJ and BMS. All authors contributed to the research design and interpretation of the results and critical revision of the manuscript for important intellectual content. All authors approved the final version of the manuscript. LRR attests that all listed authors meet authorship criteria and that no others meeting the criteria have been omitted. LRR is the guarantor of this work and, as such, had full access to all the data in the study and takes responsibility for the integrity of the data and the accuracy of the data analysis. The manuscript is an honest, accurate and transparent account of the study being reported that no important aspects of the study have been omitted.

\section{Funding}

The NIHR Exeter Clinical Research Facility is a partnership between the University of Exeter Medical School College of Medicine and Health, and Royal Devon and Exeter NHS Foundation Trust. The EXTEND/PRB project is supported by the National Institute for Health Research (NIHR) Exeter Clinical Research Facility. AGJ is funded by an NIHR Clinician Scientist award (CS2015-15-018). JD is supported by an Independent Fellowship funded by Research England's Expanding Excellence in England (E3) fund. TJM is funded by an NIHR Senior Clinical Lectureship.

\section{Availability of data and materials}

The authors do not have permission to share these data. Access to the EXTEND/PRB resource is governed and approved by the Peninsula Research Bank Steering Committee. Requests for access to original data should be in the form of a formal application the Peninsula Research Bank details can be found at: https://exetercrfnihr.org/about/exeter-10000-prb/.

\section{Declarations}

\section{Ethics approval and consent to participate}

This commitment to ensuring effective patient and public involvement in all stages of research is central to projects undertaken within the Exeter Clinical Research Facility [42]. The lay members of the committee were enthusiastic on the project aims and voted overwhelmingly to support the research team by approving access to the required data.

EXTEND/PRB ethical approval number: 14/SW/1089 (5-year extension following initial approval - 09/H0106/75)

\section{Consent for publication}

Not applicable.

\section{Competing interests}

ZC reports grants and non-financial support from Celgene, grants and nonfinancial support from Merck Sharpe \& Dohme, grants and non-financial support from Amgen, grants and non-financial support from Takeda, outside the submitted work.

\section{Author details}

${ }^{1}$ Institute of Health Research, University of Exeter Medical School, South Cloisters, St Lukes Campus, Exeter EX1 2LU, UK. ${ }^{2} \mathrm{NIHR}$ Exeter Clinical Research Facility, Royal Devon \& Exeter NHS Foundation Trust \& University of Exeter Medical School, Exeter, UK. ${ }^{3}$ Institute of Biomedical and Clinical Science, College of Medicine and Health, University of Exeter, Exeter EX2 5DW, UK. ${ }^{4}$ Clinical Trials Research Unit, Leeds Institute of Clinical Trials Research, University of Leeds, Leeds, West Yorkshire, UK. ${ }^{5}$ College of Mathematics Engineering and Physical Science, University of Exeter, Exeter, UK. ${ }^{6}$ Department of Diabetes and Endocrinology, Royal Devon and Exeter NHS Foundation Trust, Exeter, UK. ${ }^{7}$ Academic Department of Blood Sciences, Royal Devon and Exeter NHS Foundation Trust, Exeter, UK.
Received: 3 March 2021 Accepted: 7 July 2021

Published online: 20 August 2021

\section{References}

1. Cho NH, Shaw JE, Karuranga S, Huang Y, da Rocha Fernandes JD, Ohlrogge AW, et al. IDF Diabetes Atlas: global estimates of diabetes prevalence for 2017 and projections for 2045. Diabetes Res Clin Pract. 2018;138:271-81.

2. Zhou B, Lu Y, Hajifathalian K, Bentham J, Di Cesare M, Danaei G, et al. Worldwide trends in diabetes since 1980: a pooled analysis of 751 population-based studies with 4.4 million participants. Lancet. 2016; 387(10027):1513-30.

3. Gray LJ, Troughton J, Khunti K, Davies MJ. Let's Prevent Diabetes: from idea to implementation. Pract Diabetes. 2017;34(2):55-7.

4. The Diabetes Prevention Program (DPP) Research Group. The Diabetes Prevention Program (DPP): description of lifestyle intervention. Diabetes Care. 2002;25:2165-71.

5. Gillies CL, Abrams KR, Lambert PC, Cooper NJ, Sutton AJ, Hsu RT, et al. Pharmacological and lifestyle interventions to prevent or delay type 2 diabetes in people with impaired glucose tolerance: systematic review and meta-analysis. Br Med J. 2007;334(7588):299.

6. Barry E, Roberts S, Oke J, Vijayaraghavan S, Normansell R, Greenhalgh T. Efficacy and effectiveness of screen and treat policies in prevention of type 2 diabetes: Systematic review and meta-analysis of screening tests and interventions. BMJ. 2017;356:16538.

7. Knowler W, Barrett-Connor E, Fowler SE, Hamman RF, Lachin JM, Walker EA, et al. Reduction in the incidence of type 2 diabetes with lifestyle intervention or metformin. N Engl J Med. 2002;346:393-403.

8. Lindström J, Peltonen M, Eriksson JG, Aunola S, Hämäläinen $\mathrm{H}$, et al. Determinants for the effectiveness of lifestyle intervention in the Finnish Diabetes Prevention Study. Diabetes Care. 2008;31:854-62.

9. Nathan DM, Barrett-Connor E, Crandall JP, Edelstein SL, Goldberg RB, Horton ES, et al. Long-term effects of lifestyle intervention or metformin on diabetes development and microvascular complications over 15-year follow-up: the Diabetes Prevention Program Outcomes Study. Lancet Diabetes Endocrinol. 2015;3:866-75

10. Wareham NJ. Mind the gap: efficacy versus effectiveness of lifestyle interventions to prevent diabetes. Lancet Diabetes Endocrinol. 2015;3(3): 160-1.

11. Barry E, Roberts S, Finer S, Vijayaraghavan S, Greenhalgh T. Time to question the NHS diabetes prevention programme. BMJ. 2015;351:h4717.

12. Richardson E, Zaletel J, Nolte E, On behalf of Joint Action CHRODIS. POLICY BRIEF National Diabetes Plans in Europe: What lessons are there for the prevention and control of chronic diseases in Europe? Available from: https://www.euro.who.int/_data/assets/pdf_file/0009/307494/National-dia betes-plans-Europe.pdf. Cited 2021 Jan 20.

13. Roberts S, Barry E, Craig D, Airoldi M, Bevan G, Greenhalgh T. Preventing type 2 diabetes: systematic review of studies of cost-effectiveness of lifestyle programmes and metformin, with and without screening, for pre-diabetes. BMJ Open. 2017;7:e017184 BMJ Publishing Group.

14. National Health Service. NHS England impact analysis of implementing NHS diabetes prevention programme, 2016 to 2021. Available from: https://www england.nhs.uk/wp-content/uploads/2016/08/impact-assessment-ndpp.pdf. Cited 2021 May 4.

15. National Institute for Health and Care Excellence. Type 2 diabetes prevention: population and community-level interventions. NICE guideline PH35; 2011.

16. Gillett M, Brennan A, Blake L, Payne N, Goyder L, Buckley Woods H, et al. Prevention of type 2 diabetes: preventing pre-diabetes among adults in high-risk groups. Report on use of evidence from effectiveness reviews and cost-effectiveness modelling. 2010. Available from: https://www.nice.org.uk/ guidance/ph35/evidence/report-on-costeffectiveness-evidence-andmethods-for-economic-modelling-pdf-68912173. Cited 2021 May 13.

17. National Institute for Health and Care Excellence. PH38: type 2 diabetes: prevention in people at high risk. NICE guideline PH38; 2012.

18. Gray L, Taub NA, Khunti K, Gardiner E, Hiles S, Webb DR, et al. The Leicester Risk Assessment score for detecting undiagnosed type 2 diabetes and impaired glucose regulation for use in a multiethnic UK setting. Diabet Med. 2010;27:887-95.

19. Griffin SJ, Little PS, Hales CN, Kinmonth AL, Wareham NJ. Diabetes risk score: towards earlier detection of type 2 diabetes in general practice. Diabetes Metab Res Rev. 2000;16(3):164-71. 
20. Kilpatrick ES, Atkin SL. Using haemoglobin A1c to diagnose type 2 diabetes or to identify people at high risk of diabetes. BMJ. 2014;348: g2867.

21. Richter B, Hemmingsen B, Metzendorf M-I, Takwoingi Y. Development of type 2 diabetes mellitus in people with intermediate hyperglycaemia. Cochrane Database Syst Rev. 2018;(10) Art. No.:CD012661. https://doi. org/10.1002/14651858.CD012661.pub2..

22. Morris DH, Khunti K, Achana F, Srinivasan B, Gray LJ, Davies MJ, et al. Progression rates from $\mathrm{HbA1C}$ 6.0-6.4\% and other prediabetes definitions to type 2 diabetes: a meta-analysis. Diabetologia. 2013;56(7): 1489-93.

23. Beulens J, Rutters F, Rydén L, Schnell O, Mellbin L, Hart H, et al. Risk and management of pre-diabetes. Eur J Prev Cardiol. 2019;26(2_suppl):47-54.

24. Schmidt MI, Bracco PA, Yudkin JS, Bensenor IM, Griep RH, Barreto SM, et al. Intermediate hyperglycaemia to predict progression to type 2 diabetes (ELSA-Brasil): an occupational cohort study in Brazil. Lancet Diabetes Endocrinol. 2019;7(4):267-77.

25. Mostafa SA, Khunti K, Srinivasan BT, Webb D, Gray LJ, Davies MJ. The potential impact and optimal cut-points of using glycated haemoglobin, $\mathrm{HbA1c}$, to detect people with impaired glucose regulation in a UK multi-ethnic cohort. Diabetes Res Clin Pract. 2010; 90(1):100-8.

26. Tabák AG, Herder C, Rathmann W, Brunner EJ, Kivimäki M. Prediabetes: a high-risk state for diabetes development. Lancet. 2012;379(9833):2279-90.

27. NHS England. NHS England impact analysis of implementing NHS diabetes prevention programme, 2016 to 2021. 2016.

28. Office for National Statistics. Population estimates for the UK, England and Wales, Scotland and Northern Ireland, provisional. Available from: https://www.ons.gov. uk/peoplepopulationandcommunity/populationandmigration/populationestima tes/bulletins/annualmidyearpopulationestimates/mid2019\#toc. Cited 2020 Jun 4

29. Exeter NIHR Clinical Research Facility: Exeter 10000. Available from: https:// exetercrfnihr.org/about/exeter-10000-prb/. Cited 2020 Jun 5.

30. World Health Organisation. Definition and diagnosis of diabetes mellitus and intermediate hyperglycemia. 2006.

31. National Health Service. NHS health check. Available from: https://www.nhs. uk/Conditions/nhs-health-check/. Cited 2020 Jun 10.

32. Public Health England, NHS England. NHS Diabetes Prevention Programme NHSDPP overview and FAQ NHS England Publications Gateway Reference 05728. Available from: https://www.england.nhs.uk/wp-content/uploads/201 6/08/dpp-faq.pdf. Cited 2020 Jun 10.

33. Stokes J, Gellatly J, Bower P, Meacock R, Cotterill S, Sutton M, et al. Implementing a national diabetes prevention programme in England: lessons learned. BMC Health Serv Res. 2019;19(1):1-12.

34. Chamnan P, Simmons RK, Forouhi NG, Luben RN, Khaw KT, Wareham NJ, et al. Incidence of type 2 diabetes using proposed HbA1C diagnostic criteria in the european prospective investigation of cancer-norfolk cohort: Implications for preventive strategies. Diabetes Care. 2011;34(4):950-6.

35. Soulimane S, Simon D, Shaw J, Witte D, Zimmet P, Vol S, et al. HbA1C fasting plasma glucose and the prediction of diabetes: Inter99, AusDiab and D.E.S.I.R. Diabetes Res Clin Pract. 2011;96(3):392-9.

36. Smith JR, Greaves CJ, Thompson JL, Taylor RS, Jones M, Armstrong R, et al. The community-based prevention of diabetes (ComPoD) study: a randomised, waiting list controlled trial of a voluntary sector-led diabetes prevention programme. Int J Behav Nutr Phys Act. 2019;16(1):112.

37. Zhuo X, Zhang P, Kahn HS, Gregg EW. Cost-effectiveness of alternative thresholds of the fasting plasma glucose test to identify the target population for type 2 diabetes prevention in adults aged $\geq 45$ years. Diabetes Care. 2013;36(12):3992-8.

38. Thomas C, Sadler S, Breeze P, Squires H, Gillett M, Brennan A. Assessing the potential return on investment of the proposed UK NHS diabetes prevention programme in different population subgroups: an economic evaluation. BMJ Open. 2017;7(8):e014953.

39. Kumaravel B, Bachmann MO, Murray N, Dhatariya K, Fenech M, John WG, et al. Use of haemoglobin A1c to detect impaired fasting glucose or type 2 diabetes in a United Kingdom community based population. Diabetes Res Clin Pract. 2012;96(2):211-6.

40. Schöttker B, Rathmann W, Herder C, Thorand B, Wilsgaard T, Njølstad I, et al. $\mathrm{HbA} 1 \mathrm{c}$ levels in non-diabetic older adults - No J-shaped associations with primary cardiovascular events, cardiovascular and all-cause mortality after adjustment for confoundersin a meta-analysis of individual participant data from six cohort studies. BMC Med. 2016;14(1):1-17.
41. Christensen DL, Witte DR, Kaduka L, Jørgensen ME, Borch-Johnsen K, Mohan V, et al. Moving to an A1C-based diagnosis of diabetes has a different impact on prevalence in different ethnic groups. Diabetes Care. 2010;33(3):580-2.

42. Exeter NIHR Clinical Research Facility: Patient and Public Involvement. Available from: https://exetercrfnihr.org/public-and-patients/patient-andpublic-involvement-ppi/. Cited 2020 May 6.

\section{Publisher's Note}

Springer Nature remains neutral with regard to jurisdictional claims in published maps and institutional affiliations.
Ready to submit your research? Choose BMC and benefit from:

- fast, convenient online submission

- thorough peer review by experienced researchers in your field

- rapid publication on acceptance

- support for research data, including large and complex data types

- gold Open Access which fosters wider collaboration and increased citations

- maximum visibility for your research: over $100 \mathrm{M}$ website views per year

At BMC, research is always in progress.

Learn more biomedcentral.com/submissions 